\title{
Newborn hearing screening with transient evoked otoacoustic emission: a prospective study in a tertiary health care centre
}

\author{
Shashidhar S. Suligavi*, Prakhar Upadhyay, Prasen Reddy, S. S. Doddamani, M. N. Patil
}

Department of Ear Nose Throat, S. Nijalingappa Medical College, Bagalkot, Karnatka, India

Received: 02 April 2016

Accepted: 09 April 2016

*Correspondence:

Dr. Shashidhar S. Suligavi,

E-mail: drshashient@gmail.com

Copyright: () the author(s), publisher and licensee Medip Academy. This is an open-access article distributed under the terms of the Creative Commons Attribution Non-Commercial License, which permits unrestricted non-commercial use, distribution, and reproduction in any medium, provided the original work is properly cited.

\section{ABSTRACT}

Background: As hearing impairment is a hidden disability, it is usually detected after 2-3 years by which time there will be irreversible stunting of the skills and hence rehabilitation procedures like hearing aids, speech therapy are unable to ensure complete development of speech. Therefore hearing impairment should be diagnosed as early as 6 months to ensure timely therapy. The objective of the study is to identify the proportion of incidence of hearing impairment in neonates using transient evoked otoacoustic emissions (TEOAE) as a screening tool.

Methods: Prospective study on 800 newborns in a tertiary hospital using TEOAE. Brain stem evoked response audiometry (BERA) was used to confirm hearing loss in neonates who failed TEOAE.

Results: Thirteen out of 800 newborns failed TEOAE test on first screening. Two failed on $2^{\text {nd }}$ TEOAE test done after 3-4 weeks. Hearing loss was later confirmed in them with BERA test.

Conclusions: Proportion of hearing loss in our study was $0.25 \%$. Hearing screening should be done as early as possible so that deaf children are rehabilitated early.

Keywords: Transient evoked otoacoustic emissions, Newborns hearing screening, Brain stem evoked response audiometry

\section{INTRODUCTION}

Neonatal deafness is found to be 1-6 per 1000 live births. ${ }^{1,2}$ Hearing is a vital part of newborn's contact with environment to develop communication and language skills. As hearing impairment is a hidden disability, it is usually detected after 2-3 years by which time there will be irreversible stunting of these skills and hence rehabilitation procedures like hearing aids, speech therapy are unable to ensure complete development of speech. ${ }^{3}$ Therefore hearing impairment should be diagnosed as early as 6 months to ensure timely therapy. ${ }^{4}$ The best process for this is neonatal screening. However in a country like ours where a great number of newborns have to be screened, the method needs to be simple, quick and cost effective.
We have used TEOAE as a screening tool in our study. The demonstration of OAE by KEMP in 1978 contributed largely for the early detection of auditory deficiencies. Since then many studies were carried out and results were described. Different studies have revealed TEOAE sensitivity as high as $95 \%-98 \%$ and a specificity of $80 \%-85 \% .^{5}$ This study was conducted to estimate the proportion of newborns with hearing impairment born in a tertiary hospital using TEOAE and BERA.

\section{METHODS}

It was a prospective study of neonates born in our hospital between April 2013 to April 2015. These included normal as well as high risk babies. High risk babies were either born out of high risk pregnancy or had 
intra-natal and neonatal complications requiring NICU admission. A detailed perinatal history was taken and complete ENT examination was done. External auditary canals were cleared of any debris or wax. Newborns with external and middle ear pathologies were excluded. Parents were informed in detail about the screening study. An informed consent was taken from the parents or guardians and approval of research and ethics committee was taken.

Both normal and high risk neonates underwent hearing screening test after 48 hours of birth using TEOAE as a first level screening. Neonates who failed the first test subjected to repeat TEOAE testing after 3-4 weeks. Newborn with absence of emission for at least 3 out of 5 frequencies $\left(2,3,4,6,8 \mathrm{KH}_{\mathrm{Z}}\right)$ were declared as failures. Those who failed in second test too underwent BERA test for confirmation. The data collected was transferred to MS office excel program and statistical analysis was carried out using percentages and proportions.

\section{RESULTS}

Total of 800 newborns were screened for hearing using TEOAE, of which 424 were females and 376 were males. Thirteen newborns failed the first screening. Only 2 out of these 13 newborns failed the TEOAE test on second screening which was done about 3-4 weeks later (Table 1). Then these 2 newborns were subjected to BERA test for confirmation. One newborn had profound and other one had severe sensorineural hearing loss. Overall $0.25 \%$ newborns had hearing loss on screening (Table 2).

Table 1: Results of newborn screening.

\begin{tabular}{|llll|}
\hline TEOAE test & Pass (\%) & Fail (\%) & $\begin{array}{l}\text { Total } \\
\text { newborns }\end{array}$ \\
\hline First screening & $\begin{array}{l}787 \\
(98.36)\end{array}$ & $\begin{array}{l}13 \\
(01.64)\end{array}$ & 800 \\
\hline $\begin{array}{l}\text { Second } \\
\text { screening }\end{array}$ & $11(84.62)$ & $2(15.38)$ & 13 \\
\hline
\end{tabular}

Table 2: Distribution of hearing loss.

\begin{tabular}{|llll|}
\hline $\begin{array}{l}\text { Hearing } \\
\text { loss }\end{array}$ & Absent (\%) & Present (\%) & $\begin{array}{l}\text { Total } \\
\text { newborns }\end{array}$ \\
\hline & $798(99.75 \%)$ & $2(0.25 \%)$ & 800 \\
\hline
\end{tabular}

\section{DISCUSSION}

When hearing loss of a child goes unidentified, there is adverse effect on his speech, language development, literacy skills, academic and social development. There is significant evidence that if identification and rehabilitation is done before 6 months to 1 year of age, child will have better outcome.

Universal screening for hearing loss is based on facts like $42-70 \%$ children will be missed by risk based screening. ${ }^{7-9}$ Other one is that a critical period exists for optimal language development and earlier interventions may improve communication, self-confidence and reduce parent frustration. ${ }^{10}$

In our study, we verified that $0.25 \%$ of neonates had hearing loss and such data is close to other studies. ${ }^{11}$ This study also shows that TEOAE is a useful, non-invasive and cheaper screening tool for evaluation of hearing impairment in newborns. Similar observations have been made in other studies. ${ }^{5,12,13}$ Ideally all newborns should be screened for hearing loss. There is a need for raised community awareness regarding newborn hearing evaluation. Hearing screening, disability limitation and rehabilitation should be included in national health program.

\section{Funding: No funding sources}

Conflict of interest: None declared

Ethical approval: The study was approved by the Institutional Ethics Committee

\section{REFERENCES}

1. Bachmann KR, Arvedson JV. Early identification and intervention for children who are hearing impaired. Paediatr Rev. 1998:19;155-63.

2. Nagapoornima P, Ramesh A, Srilakshmi, Rao S, Patricia PL, Gore M, Dominic M, Swarnarekha. Universal hearing screening. Indian $\mathrm{J}$ Paedia. 2007;74:172-85.

3. Yoshinaga, Itano S, Sedey AL, Coulter DK, Mehl AL. Language of early and later identified children with hearing loss. Paediatrics. 1998;102(5):1161-71.

4. Robert MK, Bonita MD, Stanton, Joseph G, Nina FS. Nelson Textbook of Paediatrics. $18^{\text {th }}$ edition: Elsevier; 2015:2188-2196.

5. Keren R, Helfand M, Homer C, McPhilips H, Lieu TA. Projected Cost effectiveness of state wide universal newborn hearing screening. Pediatrics. 2002;110(5)855-64.

6. Marteletto J, Costa D, Furtadode V, Almeida, Piresdeoliveira CAC, Sampaio ALL. Transient and distortion product evoked oto acoustic emissions in premature infants. Intl Arch Otorhinolaryngol. Saa Paulo. 2000;13:309-16.

7. Grapo de apoio a triagen auditiva neonatal universal (GATANU). Available at Disponival em:www.gatanu.org. Accessed on 18 January 2016.

8. Hadad J. Hearing Loss In: R.E. Behrman, R. Kliegman and H.B. Jenson. Nelson Text book of Paediatrics. $17^{\text {th }}$ edition, Philadelphia: Saunders; 2004:2129-2134.

9. White KR, Vohr BR, Behrens TR. Universal newborn hearing screening using transient evoked otoacoustic emissions : results of the rhode island hearing assessment project. Seminars in Hearing. 1992;14:18-29.

10. Jewel J, Varghese PV, Singh T, Varghese A. newborn hearing screening experience at a tertiary 
hospital in NorthWest India. Int J Otolaryngology Head Neck Surg. 2013;2:211-4.

11. Stevens JC, Webb HD, Hutchinson J, Buffin JT, Smith MF. Otoacoustic emission. Int J Pedia Otorhinolaryngology. 1995;32:213-6.

12. Norton SJ, Gorga MA, Widen JE, Folsom RC, Singer Y, Cone WB et al. Identification of neonatal hearing impairment: evaluation of transient evoked otoacoustic emissions, distortion product otoacoustic emissions and auditory brainstem response test performances. Ear and Hearing. 2000;21:508-28.

13. Jewel J, Varghese PV, Singh T, Varghese A. newborn hearing screening experience at a tertiary hospital in northwest India. Int J Otolaryngology Head Neck Surg. 2013;2:211-4.

Cite this article as: Suligavi SS, Upadhyay P, Reddy P, Doddamani SS, Patil MN. Newborn hearing screening with transient evoked otoacoustic emission - a prospective study in a tertiary health care centre. Int $\mathbf{J}$ Otorhinolaryngol Head Neck Surg 2016;2:125-7. 